\title{
Nature experience promotes preference for and willingness to coexist with wild animals among urban and suburban residents in Malaysia
}

\author{
Huda Farhana Mohamad Muslim ${ }^{1,2^{*}}$ (D), Hosaka Tetsuro ${ }^{3}$, Numata Shinya ${ }^{2}$ and Noor Azlin Yahya ${ }^{1}$
}

\begin{abstract}
Introduction: A decline in direct experience with nature can lead to disaffection of natural environments, wildlife, and public indifference towards biodiversity conservation. This study measured on affective attitude towards wildlife (i.e., preferences for and willingness to coexist with 22 animal species) and examined the relationships between these attitudes and childhood experiences with nature.

Methods: A face to face interview was carried out in rapidly urbanizing Malaysia for both urban and suburban 357 adults (age $>20$ years old).

Results: It found that Malaysian people liked several insects and squirrels, but disliked mammals generally. Mediation analysis, with controlling sociodemographic factors (gender, age and ethnicity), showed that childhood nature experience was positively associated with preference for wild animals (standardized path coefficient $=0.18$; $p<0.001$ ), and the preference had a strong correlation with willingness to coexistence (standardized path coefficient $=0.61 ; p<0.001$ ) with the animals. Childhood nature experience, however, had limited effects on willingness to coexist with the animals via the preference, particularly for unfavourable animals. These results suggest that preference and willingness scores, even though they were significantly correlated, were different sides of affective attitudes toward animals.

Conclusions: Therefore, to promote biodiversity conservation programs, we need strategies to increase acceptance of wild animals via relevant environmental education and public communication, as well as opportunities for nature activities for children.
\end{abstract}

Keywords: Childhood, Tropical biodiversity, Nature experience, Perception, Southeast Asia

\section{Introduction}

Presence of habitats of wild animals and plants in urban areas improves the quality of life for urban dwellers (Dearborn and Kark 2009). The concept of biodiversity applies to all types of organisms, including those perceived by humans as favorable and unfavorable; such public preferences are known to have strong effects on the level of public support for species conservation

\footnotetext{
* Correspondence: hudafarhana@frim.gov.my; ladyfarhana@gmail.com

${ }^{1}$ Forest Research Institute Malaysia (FRIM), 52109 Kepong, Selangor, Malaysia

${ }^{2}$ Department of Tourism Science, Graduate School of Urban Environmental Science, Tokyo Metropolitan University, 1-1 Minami Osawa, Hachioji, Tokyo 192-0397, Japan

Full list of author information is available at the end of the article
}

projects (Martin-Lopez et al. 2007; Mir et al. 2015). People are more willing to support conservation of esthetic, large, or human-like animal species (Gunnthorsdottir 2001). Unlike conservation in protected areas far from human dwellings, urban biodiversity conservation addresses people and wild animals living together or near each other. An increase in interactions between people and wild animals could lead to an increase in human-wildlife conflicts (Hosaka and Numata 2016). Therefore, an understanding of public attitudes toward animals is critical in obtaining wide support for biodiversity conservation in urban areas. 
People generally tend to like species that they deem esthetically pleasing, such as birds, butterflies, and squirrels (Taylor and Signal 2005; Schlegel and Rupf 2010). In contrast, people tend to dislike invertebrates (other than butterflies), snakes, or pests such as mosquitoes or rats (Kaltenborn et al. 2006; Soulsbury and White 2016), although the Japanese are known to have a higher appreciation for insects than cultures (Hogue 1987). However, few studies have documented public perceptions of and preferences for wild animals in Southeast Asia (however, cf. Nik Mohamad 2011; Baharuddin et al. 2013; Jenks et al. 2014; Karuppannan et al. 2014).

The animals that people like may not be the same animals preferred to be present within them. For example, many of us may like elephants but do not want to have them near residential areas because elephants can cause damage. Thus, attitudes toward animals and problems associated with animals have been studied intensively in the context of tolerance (i.e., the level of acceptability toward the existence of wild animals or the problems caused), rather than in the context of willingness to coexist with them (i.e., the level of willingness to live close to the animals). It is important to understand the factors influencing affective attitudes (i.e., preference and willingness to coexist, in this study) toward wild animals to design effective educational programs that will enhance such attitudes.

Attitudes are known to vary greatly according to sociodemographic factors (e.g., Kellert et al. 1996; Dickman 2010), including age (Sakurai et al. 2014), gender (Kellert and Berry 1987; Herzog 2007), ethnicity (Bencin et al. 2016), and residential area (Lindsey et al. 2005). Kellert and Wilson (1993) proposed a biophilia hypothesis that humans have an innate tendency to affiliate with living organisms and Nabhan and St Antoine (1993) further hypothesized that biophilia is triggered by experiences of nature at early developmental stages. Past research from China and Japan using general linear mixed model (GLMM) and descriptive analysis have supported these hypotheses with the evidence that children involved in nature activities frequently exhibit higher preferences toward wild animals than those who experience nature less frequently (Zhang et al. 2014; Soga et al. 2016).

However, long-term effects of childhood experience are uncertain. The importance of childhood experience on adult attitudes especially on their willingness to coexist (Coexistence) toward wild animals remains unclear. These shortcomings of surveys on children can be solved by conducting a survey on adults that examine the relationship between childhood nature experience and current attitudes toward wild animals.

Understanding the effect of nature experience is an urgent issue because such experiences are globally declining due to urbanization and lifestyle changes (Miller 2005;
Soga and Gaston 2016). In the present study, we hypothesized that Malaysians with more experiences of nature in childhood (hereafter Experience) would show more positive affective attitudes toward wild animals, in terms of (i) likes and dislikes (hereafter Preference) and (ii) willingness to coexist (hereafter Coexistence). Besides Experience, we examined several sociodemographic factors to control the possible confounding effects on attitudes and to evaluate the relative importance of Experience and sociodemographic factors. We also assumed a path from preference to coexistence because preference is often an important factor that affects attitudes toward wild animals, such as tolerance (Hosaka et al. 2017) and willingness for conservation (Zhang et al. 2014; Soga et al. 2016). With these objectives, we developed a mediation model and examined this model using questionnaire data from 357 Malaysian adult residents (urban and suburban) in and around Kuala Lumpur, the capital city of Malaysia.

Malaysia, 1of the12 megadiverse countries of the world, is a developing and urbanizing country in Southeast Asia (Global Diversity Outlook 2001). This tropical country experienced a drastic urbanization and degradation of natural landscapes with a rapid population grew from 6.5 million in 1957 to 22 million in 2000 (Yaakob et al. 2010). The forested area of Peninsular Malaysia declined from $73 \%$ in the late 1960 s to $44 \%$ in 2001 (Vincent and Hadi 1993; Abdullah and Nakagoshi 2006). Over the same period, developed and agricultural areas increased from 1 to $3 \%$ and 24 to $51 \%$ in 1950 , expanded from $19 \%$ in 1950 to $28.4 \%$ in 1970 and $62 \%$ in 2000 (Yaakob et al. 2010). In a built environment setting, Malaysia's Town and Country Planning Act 1995 and the amendment (Act A933) 2001 had considered to protect the importance of public open spaces as one of the social infrastructures for urban dwellers, thus, lead to urban greening priorities in Peninsular Malaysia (Sreetheran et al. 2006). The National Policy on Biological Diversity Plan 2016-2025 reflects the nation's priorities for conservation and sustainable use of Malaysian biodiversity. According to this policy, a special action in Action 6.5 comprises biodiversity conservation in urban areas, enhanced the establishment of natural green networks in developed areas, and supports the development of conservation programs involving urban residents.

Our study addressed the following specific research questions: (1) Which wild animals do Malaysians like and wish to coexist with? and (2) Do Experience scores affect Preference and Coexistence scores? If so, how strong are these effects compared to the sociodemographic factors?

\section{Methods}

\section{Survey procedure}

The questionnaire survey was conducted in three urban towns (Kepong, Kuala Lumpur, and Putrajaya) (Appendix 1) 
and three suburban districts (Hulu Langat, Kuala Selangor, and Hulu Selangor) in and $<100 \mathrm{~km}$ from Kuala Lumpur. During January to March 2016, we visited every houses in the six study areas and conducted a faceto-face questionnaire survey to one adult member (age $>20$ years) for each household if he/she agreed to be involved in the survey. We had no rules in selecting the houses and continued the survey until we got c. 60 samples for each area (consequently we got 357 effective samples in total). The survey was conducted in either English or Malay. No names or identification numbers were collected from the respondents. Thus, ethics approval and written consent were not required from the municipal councils of the districts. Participants were assured that individual responses would be treated only as aggregate data for scientific research purposes, without any profit or marketing segmentation implications.

\section{Questionnaire}

To assess the level of Experience, respondents were asked whether they had experienced each of the 18 activities in nature ("yes" or "no") when they were children (age $\leq 12$ years). The 18 activities included playing in rivers or waterfalls, observing wild animals, collecting flowers or fruits, collecting seeds or twigs, eating self-collected fruit, climbing trees, making kites, fishing, sliding down river banks or slopes, playing with soil or sand, making spinning tops, making flower crowns, collecting herbs or weeds, catching frogs or spiders, making a gun or boat from bamboo, and participating in traditional outdoor games. These experiences were selected based on a discussion with experts, including local environmental education researchers and the website "Malaysia games without gadgets" (Traditional games in Malaysia 2016). Only activities that involved direct interactions with plants, animals, or soil were included.

Respondents rated their Preference levels using a 5point Likert scale $(5=$ like very much; $1=$ do not like at all) for 22 wild animals listed in the questionnaire. The questionnaire contained only a list of 22 animal names with no photos provided. The 22 selected wild animals included nine mammals (monkey, wild boar, civet, bat, rat, slow loris, flying squirrel, shrew, and squirrel), three birds (kingfisher, crow, and swallow), one reptile (snake), one amphibian (frog), and eight insects (beetle, cricket, cicada, butterfly, dragonfly, wasp, bee, and firefly). These animals are commonly found in urban or suburban areas in Malaysia. Although the taxonomic level varies from species to order among the animal groups, these terms were used because most people would easily recognize the animals in the questions.
To quantify the Coexistence level, respondents were asked to select the desirable places for each of the 22 animals to live in from the following four locations: $1=$ nowhere, 2 = distant park or forest, $3=$ park or nearby forest, and $4=$ anywhere, including their home garden or veranda. Respondents who did not recognize the animals were not permitted to answer the questions related to Preference or Coexistence. Prior to the main survey, a preliminary survey was conducted to around 20 staff in our research institution to check whether respondents correctly understand the questionnaire items. Questions were also asked to ascertain the sociodemographic characteristics of the respondents, such as gender, age, education level, ethnicity (Malay or non-Malay), family structure (having children or no children), annual income, and childhood residential setting (urban or suburban).

\section{Data analysis}

The mean Preference and Coexistence scores for each animal were calculated. A mediation analysis was then conducted. The total number of activities that a respondent had experienced (range 0-18) was used as Experience scores. The mean Preference score (0.0-5.0) with Cronbach's alpha value (for reliability test) is 0.903 , indicating a good level of internal consistency, and reliability was used as Preference scores. The Coexistence scores (0.0-4.0; Cronbach's alpha value is 0.97 ) were used over all animals as Coexistence scores for each respondent. Experience scores and several sociodemographic parameters (gender, age, ethnicity, education level, income, residential areas, and having children or not) were employed as explanatory variables, Coexistence scores as a response variable, and Preference scores as a mediator. However, education, income, residential area, and having children or not were excluded in this study because these factors had no significant effect on Preference or Coexistence scores. To compare the effect sizes of the parameters, standardized path coefficients were calculated. To assess the significance level of indirect effects, the standard error of estimated parameters of indirect effects was assessed using a bootstrap method (1000 iterations) (Rosseel 2012; Zainuddin 2015). The overall fit of the models was determined by the root mean square error of approximation (RMSEA) and comparative fit index (CFI). The goodness of fit was assessed based on the following criteria: RMSEA $<0.05$ and CFI $>0.95$. Mediation analysis was performed with the "lavaan" package and "sem" function (ver. 0.5-18) (Rosseel 2012) in R (ver. 3.2.1). As the effects of the parameters can differ among animal groups with different public affective attitudes, the 22 animals were classified into three groups (i.e., favorable, fairly unfavorable, and unfavorable) 
using cluster analysis (Ward method) based on Preference and Coexistence scores, and the same mediation analysis as above was performed for each animal group.

\section{Results}

There was a marked variation in Preference and Coexistence scores among the 22 animal species (Fig. 1). The animals with the highest Preference scores were insects (e.g., butterfly, dragonfly, firefly, cicada, beetle, and cricket) and squirrels. In contrast, animals with the lowest Preference scores included wild boar, rat, and bat. Similarly, respondents assigned the highest Coexistence scores to insects and squirrels, whereas the lowest to boar, rat, and civet (Fig. 1). The mean Preference and Coexistence scores of each animal were strongly positively correlated (Pearson's $r=0.90$, $p<0.001)$.

Overall results showed that Preference was positively associated with direct experience with nature (see Fig. 6a in Appendix 2). This suggests that Malaysians who had greater experience of nature in childhood showed higher Preference scores $(r=0.13$, $p<0.01)$ than those who had less nature experience. However, Coexistence scores did not correlate with direct experience with nature $(r=0.04, p=0.49)$ (see Fig. 6b in Appendix 2).

\section{Path analysis}

The hypothesized model exhibited a good fit with the data (RMSEA $=0.00, C F I=1.00$; Fig. 2). There was no significant direct path from Experience to Coexistence for all animal species. However, Experience had a significant positive effect on Preference, and Preference had a significant positive effect on Coexistence (Fig. 2). Consequently, both the indirect and the total effects of Experience on Coexistence were significant (Table 1). It showed that, among the explanatory parameters considered, Experience had the strongest effect on both Preference (Fig. 2) and Coexistence scores (Table 1).

However, gender had no significant path to Preference but had a significant path to Coexistence; males were more willing to have wild animals nearby than females. Age and ethnicity (Malay) had a positive path to Preference suggesting that older people and the Malays liked animals more than the young and non-Malays did, respectively for all animal species (Fig. 2).

The 22 animal species were classified into three groups as shown in Ward's dendrogram of a hierarchical cluster analysis (Fig. 3). Cluster 1 consisted of insects (butterfly, dragonfly, firefly, and cicada) and squirrel. Cluster 2 consisted of birds (swallow and kingfisher), insects (beetle, cricket, bee, and wasp), and frog. Cluster 3 consisted of mammals (flying squirrel, shrew, slow loris, monkey, civet, bat, rat, and wild boar), snake, and crow (Fig. 2). Mean Preference and Coexistence scores were highest for cluster 1 (Preference $=3.40$, Coexistence $=3.11)$, followed by cluster 2 (Preference $=2.88$, Coexistence $=2.76)$ and cluster 3 (Preference $=2.38$, Coexistence $=2.24$ ) (Fig. 1), suggesting that these

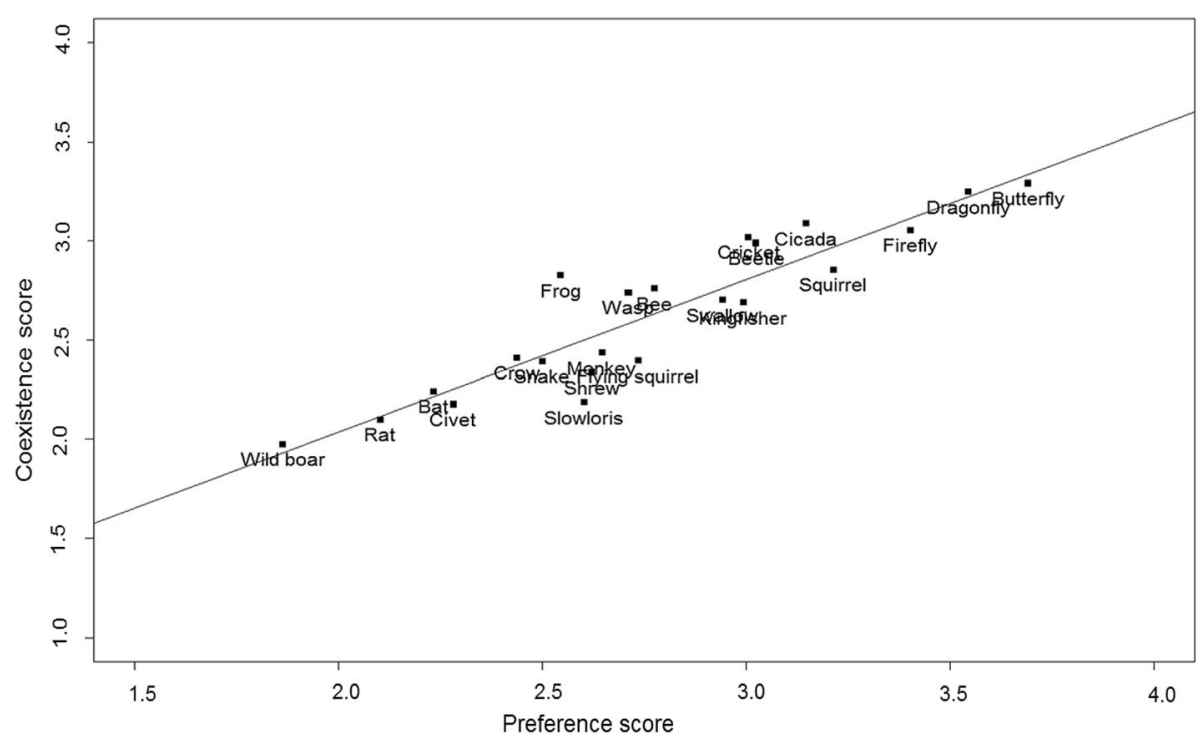

Fig. 1 Preference and Coexistence scores for the 22 wild animal species. Species classifications were based on Ward's dendrogram of a hierarchical cluster analysis (clusters 1-3) (see also Fig. 2) 


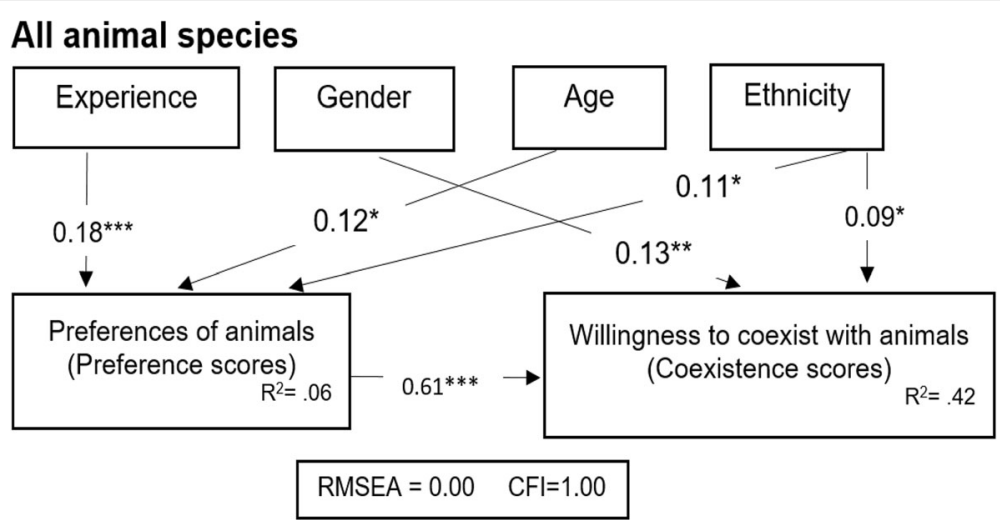

Fig. 2 Model with standardized estimates (non-significant paths not shown) predicting Preference and Coexistence using sociodemographic factors, namely, sex (male $=1$, female $=0$ ), age, ethnicity (Malay $=1$, non-Malay $=0$ ), and Experience level. Asterisks indicate significance levels $\left({ }^{*} p<0.05 ;{ }^{* *} p<0.01 ;{ }^{* * *} p<0.001\right)$

clusters indicate favorable, fairly unfavorable, and unfavorable animals, respectively.

Meanwhile, Experience did not have a significant direct path to Coexistence but had a significant effect on Preference, and Preference had a strong effect on Coexistence for all cluster animals (Fig. 4). Therefore, the indirect effect of Experience on Coexistence was always significant, but its total effect was not significant for cluster 3 (Table 1).

The effects of sociodemographic factors differed among clusters. Males had higher Preference scores for cluster 1 and Coexistence scores for cluster 2 than females. Age had a positive effect on Preference for clusters 1 and 2 but a negative effect on Coexistence for cluster 2. The Malays had higher Preference scores for clusters 1 and 2 and higher Coexistence scores for cluster 2 than non-Malay (Fig. 4). None of the sociodemographic factors had a significant effect on Preference or Coexistence scores for cluster 3. Based on the standardized path coefficients, Experience had the strongest or second strongest effect on Preference for all clusters. The total effect of

Table 1 The standardized path coefficients for direct, indirect, and total effects on willingness to coexist (Coexistence) with wild animals (see Figs. 2 and 4 for further details). Male and Malay are the reference categories for gender and ethnicity, respectively

\begin{tabular}{|c|c|c|c|c|}
\hline Path analysis & Variables & Direct (c) & Indirect $(a \times b)$ & Total effect $[(a \times b)+c]$ \\
\hline \multirow[t]{4}{*}{ All species (22 species) } & Experience & 0.056 & $0.107^{* *}$ & $0.163^{* *}$ \\
\hline & Gender & $0.125^{* *}$ & 0.025 & $0.150^{* *}$ \\
\hline & Age & -0.061 & $0.075^{*}$ & 0.014 \\
\hline & Malay & $0.094^{*}$ & 0.059 & $0.153^{* *}$ \\
\hline \multirow[t]{4}{*}{ Path cluster 1 ( 5 species) } & Experience & 0.079 & $0.108^{* * *}$ & $0.187^{* * *}$ \\
\hline & Gender & 0.084 & $0.112^{* * *}$ & $0.196^{* * *}$ \\
\hline & Age & -0.034 & $0.071^{*}$ & 0.037 \\
\hline & Malay & 0.072 & $0.087^{* *}$ & $0.159^{* *}$ \\
\hline \multirow[t]{4}{*}{ Path cluster 2 (7 species) } & Experience & 0.092 & $0.075^{*}$ & $0.167^{* *}$ \\
\hline & Gender & $0.156^{* * *}$ & 0.028 & $0.184^{* * *}$ \\
\hline & Age & $-0.089^{*}$ & $0.088^{* *}$ & -0.001 \\
\hline & Malay & $0.118^{* *}$ & $0.071^{*}$ & $0.189^{* * *}$ \\
\hline \multirow[t]{4}{*}{ Path cluster 3 (10 species) } & Experience & 0.007 & $0.065^{*}$ & 0.072 \\
\hline & Gender & 0.013 & -0.003 & 0.010 \\
\hline & Age & 0.004 & -0.003 & 0.001 \\
\hline & Malay & 0.097 & -0.050 & 0.047 \\
\hline
\end{tabular}

The level of significance is ${ }^{*} p<0.05,{ }^{* *} p<0.01,{ }^{* * *} p<0.001$ 


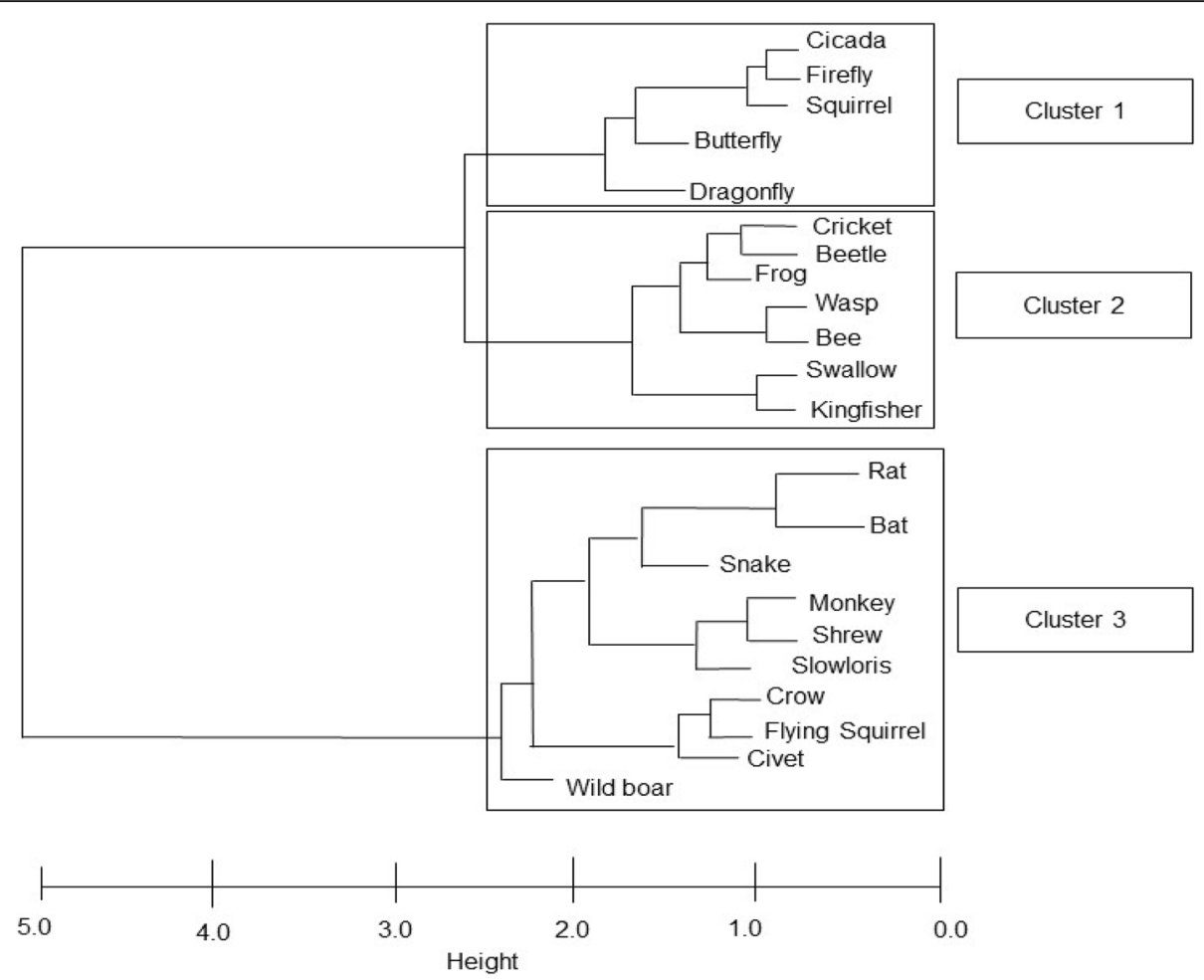

Fig. 3 Ward's dendrogram of a hierarchical cluster analysis conducted on 22 animal species

Experience was comparable to those of other factors, although gender had the strongest effect on Coexistence for clusters 1 and 2 .

\section{Discussion}

\section{Preference for and willingness to coexist with wild} animals

The most favorable animals among Malaysians were insects, for example, butterfly, dragonfly, and firefly, as well as squirrel. Appreciation for butterflies and squirrels is consistent with the previous studies in Norway (Bjerke and Østdahl 2004), America (Kellert 1984), Japan (Soga et al. 2016), and Slovakia (Prokop and Tunnicliffe 2010). Although insects other than butterflies are generally deemed unfavorable in Western countries, Malaysians tend to like several types of insects, which is consistent with the findings of the studies of Japanese people (Hogue 1987). Since Coexistence scores were also high for these animals, insects would be good candidates for flagship species in urban biodiversity conservation in Malaysia.

In contrast, Preference scores for birds were relatively low, although birds are often among the most popular animals (e.g., Norris and Pain 2002; Schlegel and Rupf 2010). However, a previous study showed that small birds are the most favorable animals among urban
Malaysians (Nik Mohamad 2011). Kingfishers, swallows, and crows might not be good representatives of "small birds" for urbans. Therefore, this result might be partly due to our choice of bird species. It would be necessary to determine which bird species are popular among Malaysian urban people to select relevant flagship bird species.

All mammals except squirrels received lower Preference and Coexistence scores. This result is inconsistent with those of previous studies that showed higher appreciation for large mammals in America, Germany (Kellert 1996), and East Africa (Kaltenborn et al. 2006). Conversely, a previous study in Japan also found lower Coexistence scores for mammals by the Japanese (Hosaka et al. 2017b). Therefore, a relatively positive attitude toward insects and negative attitude toward mammals might be the characteristic of Asians.

The assignment of the lowest Preference and Coexistence scores to wild boar was probably due to religion. The Malays are predominately Muslim and consider the wild boar and pig as taboo. Also, wild boars are pests that often cause damage to agricultural crops and sometimes also injure people. For example, the number of complaints about boars is the second greatest after the macaque among complaints about wild animals in Malaysia (Department of Wildlife and National Parks 2015). 


\section{Cluster 1 (Favorable)}

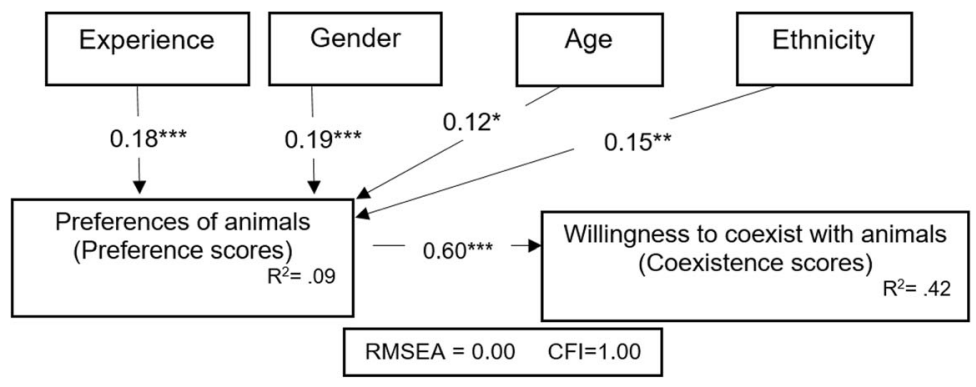

Cluster 2 (Fairly unfavorable)

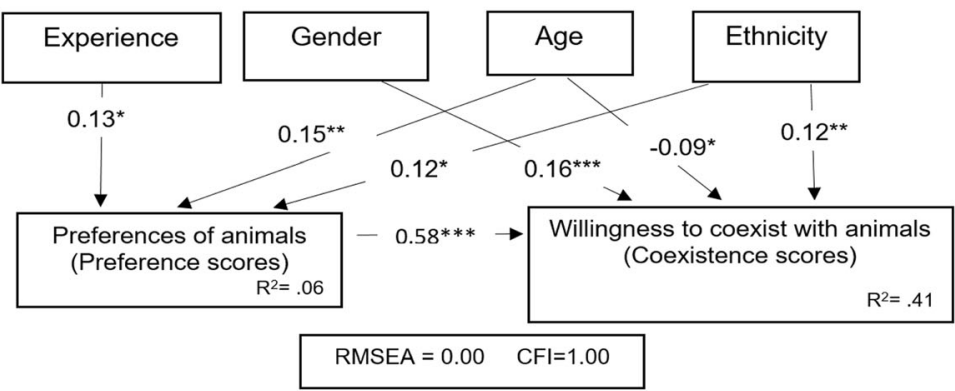

\section{Cluster 3 (Unfavorable)}

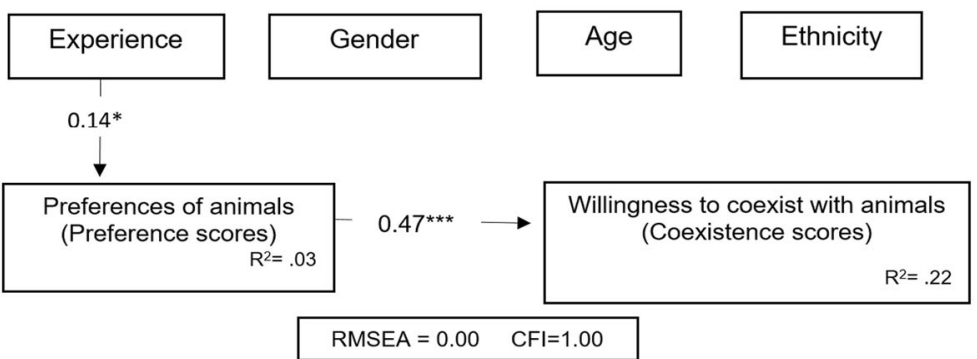

Fig. 4 The best SEM (clusters 1-3) with standardized estimates of parameters (non-significant paths omitted), predicting Preference and Coexistence for species grouped into clusters 1, 2, and 3 (see Fig. 1). Asterisks indicate significance levels $\left({ }^{*} p<0.05 ;{ }^{* *} p<0.01 ;{ }^{* * *} p<0.001\right)$

The number of species with Preference scores higher than the neutral point (average 3.0) was only 7 of 22 species. Although it is difficult to compare this result directly with those of other studies due to the differences in animals selected, 15 of 21 species in Tanzania (Kaltenborn et al. 2006), 11 of 24 species in Norway (Bjerke and Østdahl 2004), and 16 of 29 species in Japan (Hosaka et al. 2017b) had Preference scores higher than neutral. Therefore, Malaysians might have lower interest and appreciation for common wild animals than citizens of other countries.

Overall, we observed that the Preference and Coexistence scores were strongly positively correlated and suggested that people are willing to have animals that they like nearby their house. Hosaka et al. (2017b) reported that the Japanese are not willing to have almost all mammals nearby their house even though these mammals are liked by many people. But this pattern was less unclear in the present study as it might be other possible factors that affecting Preference such as media coverage. The straightforward relationship between Preference and Coexistence may be partly due to disinterest, but problem-causing wildlife such as elephant and tiger have extinct from the study areas.

Activities for the protection and sustainable use of biodiversity are typically focused on national parks and sanctuaries in Malaysia and remain scarce in urban or suburban areas with few exceptions, for example, firefly conservation in Kuala Selangor (Nada and Kirton 2004). Thus, the findings of this study will be useful for selecting flagship animals in urban areas in Malaysia. 


\section{Factors affecting preference and willingness for} coexistence

The study found that Experience had a significant positive effect on Preference and Coexistence scores for all animals combined. This is consistent with the findings of previous studies, which shown that childhood nature experience positively correlates with preference toward animals among children (Zhang et al. 2014; Soga et al. 2016). This study further demonstrated that the effect of nature experiences in childhood can persist until adulthood. This result supports the hypothesis that biophilia is triggered by nature experiences in childhood (Nabhan and St Antoine 1993).

The findings of this study are also consistent with the extinction of experience hypothesis (Miller 2005); people with little contact with nature will have little interest in or appreciation for the natural world. A consequence of this may further reduce local and global natural environments and biodiversity. Therefore, providing urban residents and children in particular with opportunities to interact with nature should be considered a high priority in urban biodiversity conservation programs.

Besides Experience, gender, age, and ethnicity also affect Preference scores. Males tend to have higher Preference and Coexistence scores than females. This is consistent with studies performed worldwide, including in the USA (Kellert 1993), Norway (Bjerke and Østdahl 2004), Tanzania (Kaltenborn et al. 2006), China (Zhang et al. 2014), and Japan (Soga et al. 2016).

Although elder people had higher preference scores for overall animals than younger people, subgroup analysis showed that it is limited to favorable and fairly unfavorable animals. Moreover, elder people were less willing to coexist with fairly unfavorable animals. Higher preference scores by elder people than younger people for favorable animals (i.e., small birds and insects) were consistent with the studies performed in Norway (Bjerke and Østdahl 2004) and Japan (Hosaka et al. 2017b). On the other hand, lower willingness to have the fairly unfavorable animals nearby among older people might reflect their utilitarian values regarding wild animals (Kellert 1996); they are more positive toward favorable animals than younger people while they are more negative with nonfavorable animals.

This study also found that the Malays tend to like wild animals more than non-Malay (Chinese and Indian). This might be because the Malays were historically more concentrated in suburban areas than non-Malay people (Evers 1977) and therefore have a greater psychological attachment to the natural landscape and wild animals. However, further research is required to confirm this conclusion because there was a small number of non-Malay respondents $(n=51)$ in this study.

Although Experience had significant indirect effects on Preference for all types of animals, the total effect of experience on Coexistence was not significant for unfavorable animals. This was due to the smaller coefficient of the path from Preference to Coexistence for unfavorable animals, compared to that for favorable or fairly unfavorable animals. This implies that simple enhancement of preference via increasing experience or other ways may not be effective to promote public willingness to coexist with these animals. Although perceptions of wild animals other than Preference are not focused, people will also consider the nuisances, risks, and costs of having animals nearby (Kansky and Knight 2014).

How then can we promote public acceptance toward unfavorable animals? Some previous studies have shown that public information campaigns and educational programs have successfully changed public attitudes toward unfavorable animals such as snakes (Ballouard et al. 2012), toads (Tomazic 2011), and tarantulas (Kawahara and Pyle 2013). People need education about how to avoid problems caused by animals, with appropriate information about risks, because perceived risk is often much higher than actual risk (Dickman 2010; Hudenko et al. 2010). The lower acceptance among older people than younger people and among females than males has also been reported in previous studies (Siemer et al. 2009; Sakurai et al. 2014) and might reflect their concerns due to a lack of power and knowledge to deal with the problems. Educational programs for older people and females might be effective in promoting public willingness to coexist with wild animals in Malaysia. Such collective efforts toward conservation would be effective to change individual behavior (Amel et al. 2017).

\section{Conclusion and recommendations}

Our findings show that Malaysian's most favorable animals were insects, for example, butterfly, dragonfly, and firefly, as well as squirrel. The mediation analysis showed that childhood nature experience had a positive effect on preferences toward wild animals but had limited effects on willingness to coexist with the animals via the preference, particularly for unfavorable animals. These results suggest that preference and willingness scores, even though they were significantly correlated, were different sides of affective attitudes toward animals. Therefore, to promote biodiversity conservation programs, we need strategies to increase the acceptance of wild animals via relevant environmental education and public communication, as well as opportunities for nature activities for children. 


\section{Appendix 1}

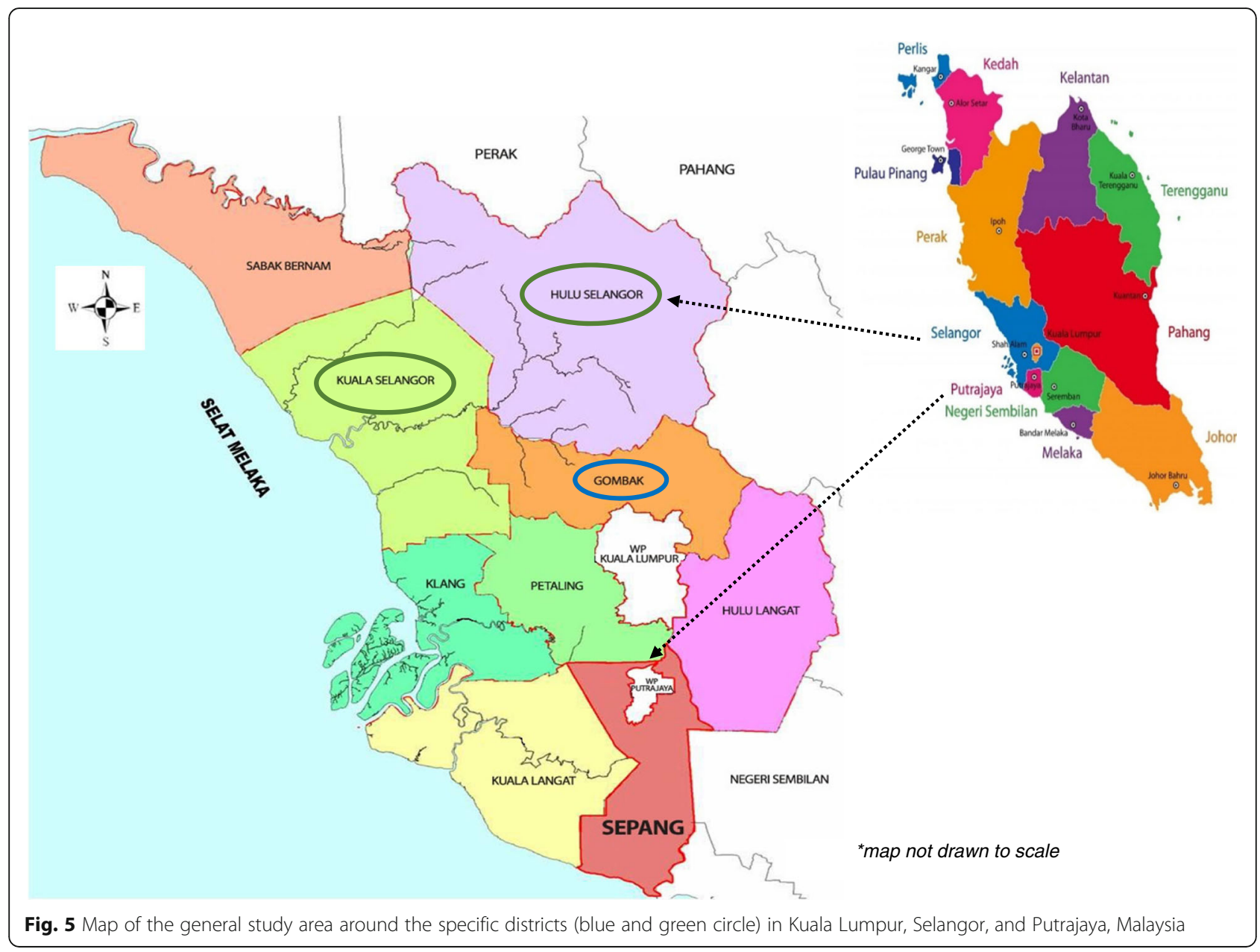




\section{Appendix 2}
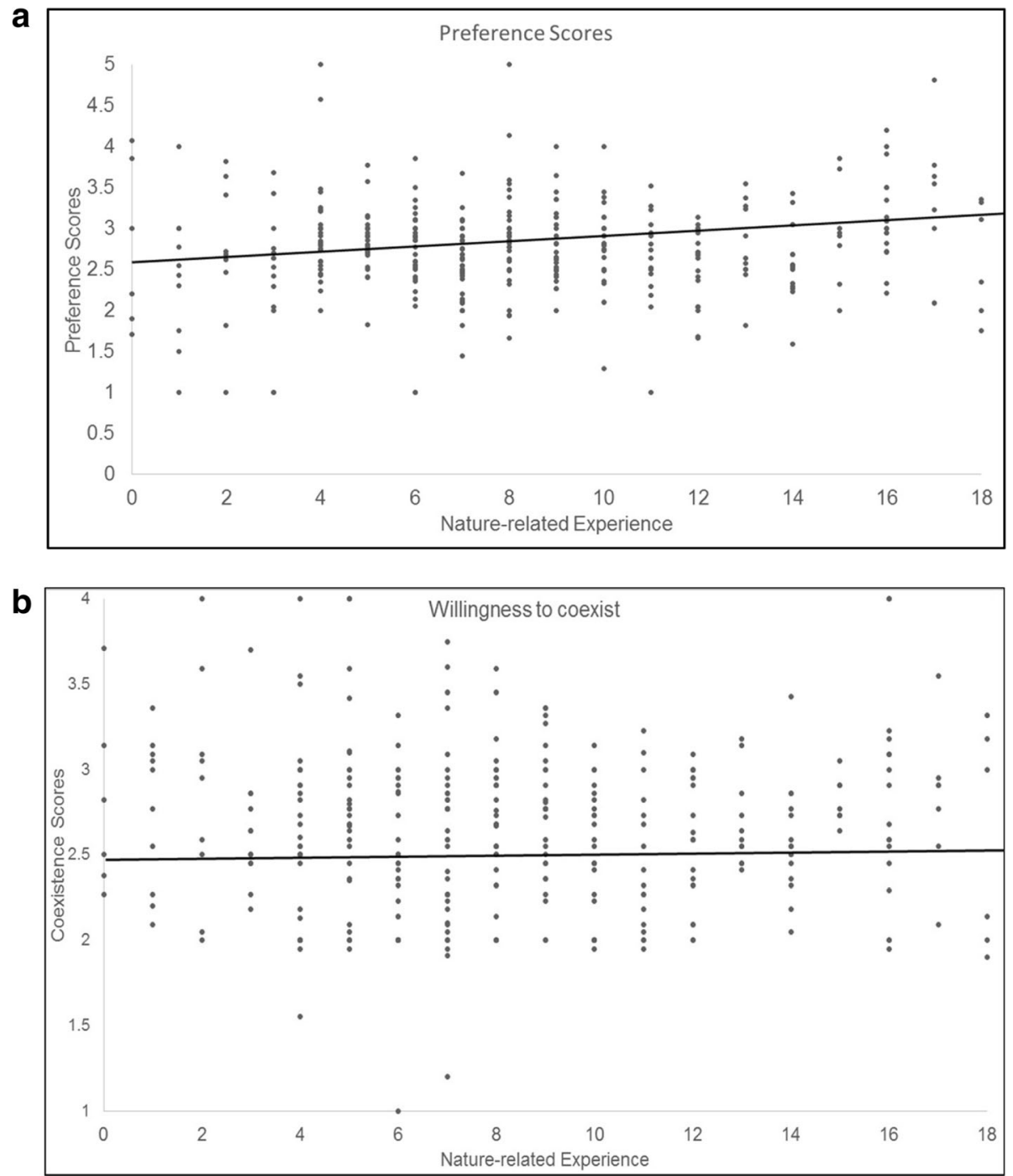

Fig. 6 Relationships between childhood nature experience and Preference and Coexistence scores. The linear regression line indicates the relationship between scores and nature experiences. a Relationships between childhood nature experience and Preference scores $(r=0.13$, $p<0.01)$. b Coexistence scores did not correlate with childhood nature experience $(r=0.04, p=0.49)$

\section{Additional file}

Additional file 1: Nature experience promotes preference for and willingness to coexist with wild animals among urban and suburban residents in Malaysia. (CSV $36 \mathrm{~kb}$ )

\section{Acknowledgements}

We thank the research team at Forest Research Institute Malaysia (FRIM) particularly from the Environmental Education Unit of the Ecotourism and Urban Forestry Programme for their full support with the questionnaire survey, Mrs. Nik Azyyati, Mrs. Naimah, and Mrs. Fatin. We thank our kind research assistants, Mrs. Alia and Mrs. Fazlina, for their time in the data compiling and data validation. The English in this document has been checked by at least two professional editors, both native speakers of English. For a certificate, please see http://www.textcheck.com/certificate/hv7RUP and refer the letter of acknowledgements as stated.

\section{Funding}

The authors were appreciating the Advanced Research Program of Asian Human Research Fund by Tokyo Metropolitan Government (TMG) for their financial support to undertake the field survey.

\section{Availability of data and materials}

The supplementary data is provided in the dataset (Additional file 1).

\section{Authors' contributions}

$\mathrm{TH}, \mathrm{SN}$, and NAY designed the concept of the study. HFMM performed the formal data analysis and data curation including necessary calculations and statistics analysis and wrote the manuscript. TH assisted in the data analysis and provided editorial assistance. TH, SN, and NAY provided substantial editor assistance and review. All authors read and approved the final manuscript.

Ethics approval and consent to participate

Not applicable. 


\section{Competing interests}

The authors declare that they have no competing interests.

\section{Publisher's Note}

Springer Nature remains neutral with regard to jurisdictional claims in published maps and institutional affiliations.

\section{Author details}

${ }^{1}$ Forest Research Institute Malaysia (FRIM), 52109 Kepong, Selangor, Malaysia. 2Department of Tourism Science, Graduate School of Urban Environmental Science, Tokyo Metropolitan University, 1-1 Minami Osawa, Hachioji, Tokyo 192-0397, Japan. ${ }^{3}$ Graduate School for International Development and Cooperation, Hiroshima University, 1-5-1, Kagamiyama, Higashihiroshima 739-8529, Japan.

\section{Received: 18 January 2018 Accepted: 14 April 2018} Published online: 30 April 2018

\section{References}

Abdullah SA, Nakagoshi N (2006) Changes in landscape spatial pattern in the highly developing state of Selangor, Peninsular Malaysia. Landsc Urban Plan 77(3):263-275

Amel E, Manning C, Scoot B, Koger S (2017) Beyond the roots of human inaction: fostering collective effort toward ecosystem conservation. Science 356:275-279

Baharuddin ZM, Karuppannan S, Sivam A (2013) Environmental attitude: values on urban wildlife. Edinb Archit Res J 33:25-46

Ballouard JM, Provost G, Barre D, Bonnet X (2012) Influence of a field trip on the attitude of schoolchildren toward unpopular organisms: an experience with snakes. J Herpetol 46:423-428

Bencin H, Kioko J, Kiffner C (2016) Local people's perceptions of wildlife species in two distinct landscapes of northern Tanzania. J Nat Conserv 34:82-92

Bjerke T, Østdahl T (2004) Animal-related attitudes and activities in an urban population. Anthrozoös 17(2):109-129

Dearborn DC, Kark S (2009) Motivations for conserving urban biodiversity. Conserv Biol 24(2):432-440

Department of Wildlife and National Parks. (2015). Annual report. Department of Wildlife and National Parks (PERHILITAN), Peninsular Malaysia, Malaysia

Dickman AJ (2010) Complexities of conflict: the importance of considering social factors for effectively resolving human-wildlife conflict. Anim Conserv 13:458-466

Evers H-D (1977) The culture of Malaysian urbanization: Malay and Chinese conceptions of space. Urban Anthropol 6(3):205-216

Global Diversity Outlook. (2001). Secretariat of the convention on biological diversity, Montreal

Gunnthorsdottir A (2001) Physical attractiveness of an animal species as a decision factor for its preservation. Anthrozoös 14(4):204-215

Herzog H (2007) Gender differences in human-animal interactions: a review. Anthrozoös 20(1):7-21

Hogue CL (1987) Cultural entomology. Annu Rev Entomol 32:181-199

Hosaka T, Numata S (2016) Spatiotemporal dynamics of urban green spaces and human-wildlife conflicts in Tokyo. Sci Rep 6:30911

Hosaka T, Sugimoto K, Numata S (2017) Effects of childhood experience with nature on tolerance of urban residents toward hornets and wild boars in Japan. PLoS One 12(4):e0175243

Hosaka T, Sugimoto K, Numata S (2017b) Childhood experience of nature influences the willingness to coexist with biodiversity in cities. Palgrave Commun 3:17071

Hudenko, H.W., Siemer, W.F., \& Decker, D.J. (2010). Urban carnivore conservation and management: the human dimension. In S.D. Gehrt, S.P.D Riley, B.L. Cypher (Eds.), Urban carnivores: ecology, conflict, and conservation. (pp. 21-33). Baltimore: The Johns Hopkins University Press

Jenks KE, Songsasen N, Kanchanasaka B, Leimgruber P, Fuller TK (2014) Local people's attitudes and perceptions of dholes (Cuon alpinus) around protected areas in southeastern Thailand. Trop Conserv Sci 7:765-780

Kaltenborn BP, Bjerke T, Nyahongo JW, Williams DR (2006) Animal preferences and acceptability of wildlife management actions around Serengeti National Park, Tanzania. Biodivers Conserv 15(14):4633-4649

Kansky R, Knight AT (2014) Key factors driving attitudes towards large mammals in conflict with humans. Biol Conserv 179:93-105.
Karuppannan S, Baharuddin ZM, Sivam A, Daniels CB (2014) Urban green space and urban biodiversity: Kuala Lumpur, Malaysia. Sustain Dev 7(1):1-16

Kawahara AY, Pyle RM (2013) An appreciation for the natural world through collecting, owing and observing insects. In: Lemelin RH (ed) The management of insects in recreation and tourism. Cambridge University Press, New York

Kellert SR (1984) American attitudes toward and knowledge of animals: an update. In: Fox MW, Mickley LD (eds) Advances in animal welfare science 1984/85. The Humane Society of the United States, Washington, DC, pp 177-213

Kellert SR (1993) Values and perceptions of invertebrates. Conserv Biol 7:845-855

Kellert SR (1996) The value of life; biodiversity and human society. Island Press, Washington DC

Kellert SR, Berry JK (1987) Attitudes, knowledge, and behaviors toward wildlife as affected by gender. Wildl Soc Bull 15(3):363-371

Kellert SR, Black M, Rush CR, Bath AJ (1996) Human culture and large carnivore conservation in North America. Conserv Biol 10(4):977-990

Kellert SR, Wilson EO (1993) The biophilia hypothesis. Island Press, Washington (DC)

Lindsey PA, Du Toit JT, Mills MGL (2005) Attitudes of ranchers towards African wild dogs Lycaon pictus: conservation implications on private land. Biol Conserv 125(1):113-121

Martin-Lopez B, Montes C, Benayas J (2007) The non-economic motives behind the willingness to pay for biodiversity conservation. Biol Conserv 39:67-82

Miller JR (2005) Biodiversity conservaton and the extinction of experience. Trends Ecol Evol 20(8):430-434

Mir ZR, Noor A, Habib B, Veeraswami GG (2015) Attitudes of local people toward wildlife conservation: a case study from the Kashmir Valley. Mt Res Dev 35(4):392-400

Nabhan GP, St Antoine S (1993) The loss of floral and faunal story: the extinction of experience. In: Kellert S, Wilson EO (eds) The biophilia hypothesis. Island Press, Washington, DC

Nada B, Kirton LG (2004) The secret life of fireflies. IRBM Updates 3(December 2004):2-4

Nik Mohamad NH (2011) Urban residents' attitudes toward wildlife in their neighbourhoods: the case study of Klang Valley, Malaysia. J Malays Inst Plann 9:19-36

Norris K, Pain DJ (2002) Conserving bird biodiversity: general principles and their application. Cambridge University Press, Cambridge

Prokop P, Tunnicliffe SD (2010) Effects of having pets at home on children's attitudes toward popular and unpopular animals. Anthrozoös 23(1):21-35

Rosseel Y (2012) Lavaan: an R package for structural equation modelling. J Stat Softw 48:1-36

Sakurai R, Jacobson SK, Ueda G (2014) Public perceptions of significant wildlife in Hyogo, Japan. Hum Dimens Wildl 19:88-95

Schlegel J, Rupf R (2010) Attitudes towards potential animal flagship species in nature conservation: a survey among students of different educational institutions. J Nat Conserv 18(4):278-290

Siemer WF, Hart PS, Decker DJ, Shanahan JE (2009) Factors that influence concern about human-black bear interactions in residential settings. Hum Dimens Wildl 14:185-197

Soga M, Gaston K, Yamaura Y, Kurisu K, Hanaki K (2016) Both direct and vicarious experiences of nature affect children's willingness to conserve biodiversity. Int J Environ Res Public Health 13(529):1-12

Soga M, Gaston KJ (2016) Extinction of experience: the loss of human-nature interactions. Front Ecol Environ 2:94-10

Soulsbury CD, White PC (2016) Human-wildlife interactions in urban areas: a review of conflicts, benefits and opportunities. Wildl Res 42:541-553

Sreetheran M, Philip E, Adnan M, Siti Zakiah M (2006) A historical perspective of urban tree planting in Malaysia. Unasylva 57(223):28-33

Taylor N, Signal TD (2005) Empathy and attitudes to animals. Anthrozoös 18(1):18-27

Tomazic I (2011) Reported experiences enhance favorable attitudes toward toads. Eurasia J Math Sci Technol Educ 7:253-262

Traditional games in Malaysia. (2016). http://traditionalgamescct.blogspot.my/ 2013/03/introduction-of-traditional-games.html. Accessed 08102016

Vincent JR, Hadi Y (1993) In sustainable agriculture and the environment in the humid tropics. In: National Research Council (ed) Malaysia. National Academy Press, Washington, D.C 
Yaakob U, Masron T, Masami F (2010) Ninety years of urbanization in Malaysia: a geographical investigation of its trends and characteristics. J Ritsumeikan Soc Sci Humanit 4(3):79-101

Zainuddin A (2015) SEM made simple: a gentle approach of learning Structural Equation Modeling. MPWS Rich Publication, Bangi

Zhang W, Goodale E, Chen J (2014) How contact with nature affects

children's biophilia, biophobia and conservation attitude in China. Biol Conserv 177:109-116

\section{Submit your manuscript to a SpringerOpen ${ }^{\circ}$ journal and benefit from:}

- Convenient online submission

- Rigorous peer review

- Open access: articles freely available online

- High visibility within the field

- Retaining the copyright to your article

Submit your next manuscript at $\gg$ springeropen.com 